\title{
Minimal genomic variability in Merremia mosaic virus isolates endemic in Merremia spp and cultivated tomato in Puerto Rico
}

\author{
Ali M. Idris ${ }^{1}$ M. A. Al-Saleh ${ }^{2}$ A. M Zakri' ${ }^{2}$ J. K. Brown ${ }^{1}$
}

Received: 21 April 2017/Accepted: 15 November 2017/Published online: 23 February 2018

(C) Indian Virological Society 2018

\begin{abstract}
Merremia mosaic virus (MerMV), a bipartite begomovirus, was identified for the first time as a pathogen of commercial tomato plantings. Infection of tomato by MerMV caused mild leaf curling and yellow foliar mosaic symptoms. Herein, the MerMV was identified in symptomatic Merremia quinquefolia and M. aegyptia (Convolvulaceae) plants exhibiting bright yellow or yellowgreen foliar mosaic symptoms, respectively. The fulllength begomoviral components were amplified from total DNA isolated from two wild species of Merremia and commercial tomato plants during 1991-1998. The DNA was subjected to rolling circle amplification, restriction digestion, and DNA sequencing. The resultant 19 and 26 apparently full-length DNA-A and DNA-B components were $\sim 2557$ and $\sim 2492$ bases, respectively. The 140-base common region was $97.9 \%$ identical between DNA-A and -B components, a predictive evidence for cognate DNA-A and -B components. Although the DNA-A components were highly conserved at 96-100\%, the DNAB components diverged at $\sim 89$ to $100 \%$, respectively. The overall clonal genomic features strongly suggested that MerMV lineage has been under host-selection for some time, and only recently, has undergone a host-shift, putatively, from wild convolvulaceous species to tomato
\end{abstract}

Electronic supplementary material The online version of this article (https://doi.org/10.1007/s13337-017-0412-6) contains supplementary material, which is available to authorized users.

J. K. Brown

jbrown@ag.arizona.edu

1 School of Plant Sciences, University of Arizona, Tucson, AZ 85721, USA

2 Plant Protection Department, King Saud University, Riyadh, Saudi Arabia
(Solanaceae). Phylogenetically, MerMV grouped with other bipartite begomoviruses indigenous to the Caribbean region, with MerMV DNA-A components forming three clusters, and the DNA-B components grouped in one clade. Both clades contained only one closet relative, an isolate of MerMV from Venezuela, MerMV-VE. Biolistic inoculation of $M$. quinquefolia and tomato seedlings with the DNA-A and -B components of PR68 and PR80 resulted in development of symptoms like those observed in naturallyinfected species, respectively.

Keywords Convolvulaceae - Solanaceae - Geminiviridae ssDNA · Wild host species · Whitefly-transmitted viruses

\section{Introduction}

The circular, ssDNA genome of plant viruses classified in the family, Geminiviridae is encapsidated in twinned, icosahedral or 'geminate' particles [31]. The International Committee on Taxonomy of Viruses (ICTV) recognizes nine genera in the family based on insect vector, type of host plant (monocot or dicot), and genome arrangement (bipartite or monopartite) [9, 79]. The genus, Begomovirus is the largest of all genera within the family, comprising at least 288 species, based on a $91 \%$ pairwise nt identity species cut off [17]. All of its members are transmitted by the whitefly Bemisia tabaci (Genn.) sibling species group, which feeds in plant phloem where begomoviruses are localized during infection [12, 27].

Begomoviral genomes have either a single component, referred to as monopartite are $\sim 2.8 \mathrm{~kb}$ in size, or two components, termed 'bipartite' and consisting of two $\sim 2.5$ to $2.6 \mathrm{~kb}$ circular ssDNAs. Both the monopartite and bipartite genome types occur in the Old World, but 
only the bipartite type is extant in the New World [17]. Each ssDNA component is encapsidated in a twinned, icosahedral, or 'geminate' particle $[9,45]$. In the New World, only bipartite viruses are indigenous, with one recent exception [50, 67], while both bipartite and monopartite genomes occur in the Old World. The DNA-A component of bipartite begomoviruses encodes four viral open reading frames (ORFs). The DNA-B component has one ORF each in the sense and antisense orientation, which are movement proteins involved in cell-to-cell movement and symptom development [see references in: 9, 30, 64].

The DNA-A and -B cognate genomic components of bipartite begomoviruses share an identical (or nearly so) common region (CR) sequence of approximately 160-230 nts that harbors one or more cis-acting elements, the hallmark nonanucleotide sequence present in all members of the family, Geminiviridae, TAATATTAC, and the cleavage site for the origin of replication [22, 27, 30]. Their monopartite begomoviral counterparts have an analogous intergenic region (IR) containing functionally homologous sequence elements required for replication.

A third kind of begomoviral-associated molecule consist of non-viral, circular ssDNAs that are about half-unit length in size, with respect to the associated monopartite 'helper' begomoviral genome, and are referred to as beta or alpha satellites owing to their non-viral contributions to pathogenicity and systemic infection of the host plant by the helper begomovirus $[10,11,55,70,80]$. Betasatellites are found widely associated with many, but not all, extant monopartite begomoviruses (Old World) [10, 80]. The alphasatellites are distinct from betasatellites in that they are predicted to derive from a nano-likevirus (family, Nanoviridae) progenitor, and so encode a replicase on the viral strand, referred to as Rep protein [10].

Begomoviruses have emerged in agricultural settings where the practice of monoculture crop production has become increasingly widespread, and cause diseases of food and fiber crops that result in yield loss and reduced quality. They have become particularly prevalent in irrigated production systems in the tropics, subtopics, and fringe temperate regions where the whitefly vector thrives $[6,14]$. Beginning in the 1990s, begomoviral emergence was exacerbated in the Americas, Asia, and the Mediterranean regions by the introduction on ornamental plants of the exotic B mitotype (based on the mitochondrial cytochrome oxidase I gene sequence) whitefly vector Bemisia tabaci (Genn.), a member of the Mediterranean-Middle East-North Africa clade of this cryptic species group $[12,15,16,27]$.

The widespread invasion of the Caribbean and other regions in the New World by the B mitotype is associated with its extreme polyphagy, adaptability to hot, dry climatic conditions occurring seasonally in the dry subtropics, and to the propensity to develop insecticide resistance. As a result, previously undescribed begomoviruses or those known to infect only indigenous, wild plant species in Puerto Rico [5, 6] have become important pathogens there and elsewhere in the region $[2,12,16,38,63,72]$.

In general, the role of endemic plant species as hosts of begomoviruses has been poorly studied, however, a number of perennial native plant and invasive weed species have become recognized as important reservoirs $[6,7,19,23,24,28,33,41,56,72]$. Further, studies have shown that multiple or 'mixed' begomoviral infections occur commonly in uncultivated eudicots $[2,24,51]$, including in taxonomically close and distantly-related species, as is the case for the pandemic cotton leaf curl disease complex in cotton-growing provinces of Pakistan and the Punjab region of India [68]. Infected wild plant reservoirs provide fertile grounds for interspecific and intergeneric recombination events and reassortment between begomoviruses, involving bipartite viral DNA-A and $-\mathrm{B}$ components, monopartite begomoviral genomes, and associated satellites of various types with different helper viruses. Collectively, uncultivated or wild plant species are important driving forces of virus evolution $[1,19,21,29,35,43,51,57,58,76]$.

During 1991-1998, begomovirus-like symptoms were observed in whitefly-infested, commercially grown tomato plants in Puerto Rico, and although tomato has been cultivated there for some time, these symptoms had not been observed previously. Begomovirus etiology was suspected, and preliminary studies based on DNA sequencing of the coat protein gene indicated the association of a previously undescribed begomovirus with symptomatic plants [4, 39], tentatively named Merremia mosaic virus (MerMV). Based on analysis of the full-length sequence of the DNA-A [AF0068636] and DNA-B [AY965899] components it has been accepted as a distinct species by the International Committee on Taxonomy of Viruses [17]. The results of a survey of tomato fields, based on partial viral sequence data, indicate that MerMV has become more widespread in Latin and Central America quite recently [65].

The objectives of this study were to determine whether the suspect bipartite MerMV was the causal agent of the disease of tomato, and if so, to fully characterize it, and to determine whether endemic, wild host plant reservoirs of the virus occurred in Puerto Rico. During the following year, virus isolates were collected from tomato plants in the same location where tomato plants were found to be infected by MerMV, and during an island-wide survey of symptomatic ruderal and cultivated plants, including two 
species of Merremia (Convolvulaceae) displaying viruslike symptoms that were documented during the 1950s and onward $[6,7]$.

\section{Materials and methods}

\section{Virus isolates}

Leaf samples were collected in Puerto Rico during 1991-1998 from symptomatic Merremia quinquefolia and M. aegyptia plants (Table 1), which was discovered to be among the most predominant wild species in and around commercial tomato fields where the tomato isolate was collected. The Merremia species samples exhibited bright yellow mosaic symptoms. Also, leaf samples were collected from commercial, field-grown tomato plants exhibiting mild leaf curling and yellow mosaic symptoms reminiscent of those associated with MerMV. Total nucleic acids were isolated from plants according to Doyle and Doyle [20], and stored at $-20{ }^{\circ} \mathrm{C}$.

\section{Virus detection of field-infected plants}

Begomovirus detection in M. quinquefolia and M. aegyptia and commercially-grown tomato plants in Puerto Rico was carried out using degenerate primers and polymerase chain reaction $(\mathrm{PCR})$ amplification of a fragment $(\sim 1300 \mathrm{bp})$ containing the complete $\mathrm{CP}$ gene [78]. The PCR amplicons were cloned into the pGEM-T Easy plasmid vector (Promega, Madison, WI), and the DNA sequence for each was determined, bidirectionally, and assembled. BLASTn analysis of the $1300 \mathrm{bp}$ fragment of the DNA-A component against the NCBI-Genbank database, which contains all available begomoviral sequences, indicated that the best hit for the viral sequences obtained from tomato and Merremia spp. plants shared greater than 99\% nt identity with

Table 1 Location, field host and year of collection of Merremia mosaic virus analyzed here

\begin{tabular}{llll}
\hline Sample & Year & Host species & Location \\
\hline PR04 & 1998 & Merremia aegyptica & Rio Grande \\
PR12 & 1995 & Solanum lycopersicum & Santa Isabel \\
PR23 & 1991 & S. lycopersicum & Rio Grande \\
PR37 & 1995 & M. quinquefolia & Guaynabo \\
PR68 & 1992 & M. aegyptia & Aguadilla \\
PR80 & 1997 & M. quinquefolia & Rio Piedras \\
PR85 & 1997 & M. quinquefolia & Maricao \\
PR89 & 1998 & M. quinquefoli & Maricao \\
\hline
\end{tabular}

MerMV (previously deposited), suggesting the presence of a single begomoviral species in all of the plant samples subjected to PCR-analysis.

\section{Cloning and sequencing of begomoviral genomes from with tomato and Merremia species}

Total DNA was purified from symptomatic field plants (Table 1) using the method of Doyle and Doyle (1990) with slight modifications, as described [38]. The extracted DNA was used as template in rolling circle amplification (RCA) using TempliPhi kit (Amersham Biosciences) according to manufacturer recommendations. The $0.5 \mu \mathrm{l}$ total DNA extract was incubated with $2.5 \mu$ sample buffer at $95{ }^{\circ} \mathrm{C}$ for $3 \mathrm{~min}$ and cooled on ice, then $2.5 \mu \mathrm{l}$ reaction buffer and $0.1 \mu$ enzyme mix were added and incubated at $30{ }^{\circ} \mathrm{C}$ for $18 \mathrm{~h}$. The reactions were held at $95{ }^{\circ} \mathrm{C}$ for 15 min to deactivate the enzyme. Full-length sequences for MerMV DNA-A [AF068636] and DNA-B [AY965899] reported previously [4] were used to identify differential unique restriction endonucleases for cloning genomic components of MerMV. For cloning the A component of MerMV, RCA products were digested with HindIII, resolved in $1 \%$ agarose gel and expected full length genome was eluted and ligated into HindIII-digested pGEM7Zf + . Similarly, RCA products were digested with $N c o$ I or SstI and the expected B component size product was eluted, and ligated into $N c o I-$ or SstI-digested pGEM5Zf + , respectively. These ligations were used to transform competent cells of Escherichia coli strain DH5 $\alpha$. Subsequently four clones containing the expected size for each component were selected for each sample for further analysis. The DNA sequence for each of the clones was determined, as previously described [38]. The resultant sequences were assembled using SeqMan software (DNASTAR Inc., Madison, WI).

\section{Sequence analysis of viral genomic components}

Sequences determined for cloned DNA-A and -B component amplicons were edited and assembled using SeqMan Pro software (DNASTAR, Madison, WI). Open reading frames (ORF) in the viral and complementary strands were identified using SeqBuilder (DNASTAR). The nt sequences of the A and B components of MerMV were aligned using MegAlign software (DNASTAR Inc., Madison, WI) to identify the common regions (CR) shared between the putative cognate pair of components containing the conserved regulatory elements associated with virus replication [3]. These elements included the 'iterons' consisting of directly repeated sequences predicted to bind Rep during viral replication, and those comprising the AC1 TATAbox, were identified by visual inspection of sequences. 
The complete nt sequences of the MerMV DNA-A and DNA-B components cloned from tomato plants were analyzed using a BLASTn search in GenBank [1] to identify the most closely related begomoviral genome sequences, respectively. Selected GenBank reference sequences (Table 3) were aligned with the MerMV DNA-A and DNA-B component sequences, respectively (Supplementary Table 4), and subjected to SDT analysis to calculate pairwise sequence identities, in accordance with ICTV recommendations for the Geminiviridae [17, 52, 77]. The DNA-A and -B component sequences were aligned separately using CLUSTAL $\mathrm{W}$ to estimate the optimal nt substitution model implemented in the MODELTEST3.7 software for Windows, using the likelihood ratio test and/or AIC criteria with default setting of alpha 0.01 [61]. The best-fit model selected by the Hierarchical Likelihood Ratio Test (hLRT) was used to reconstruct the phylogenetic trees using Maximum Likelihood (ML) in PAUP* 4.0.0b10 [74]. The reliability of the trees was evaluated using the standard error test to estimate confidence probabilities of the interior branch lengths, implemented in MEGA5.0 [75].

\section{Infectivity of cloned MerMV components}

To test the clones for infectivity, the PR68H11 (DNA-A) and PR68N2 (DNA-B) components cloned from Merremia or PR12H5 (DNA-A) and PR12S5 (DNA-B) cloned from tomato plants and carrying the full-length genomic components, were digested with the respective cloning restriction enzymes and used to biolistically inoculate Nictotiana benthamiana, M. quinquefolia, and tomato seedlings as described in Idris et al. [40]. Mock-inoculated and non-inoculated seedlings were included as the negative controls.

Construction of the infectious DNA-A and DNA-B component clones of MerMV were carried out using the clones PR68H11 (DNA-A) and PR68N5 (DNA-B). For the DNA-A component, an aliquot of the clone PR68H11 were digested with either HindIII/KpnI or HindIII/BglII to obtain 2065 and $1325 \mathrm{bp}$ fragments, respectively, both fragments contain a copy of CR-A. The fragments were ligated into BamHI/KpnI-digested pGreen to obtain pG-MerMVA11. For the DNA-B component, aliquots of the clone PR68N5 were with either $N c o \mathrm{I} / K p n \mathrm{I}$ or $N c o \mathrm{I} / N s i$ I to obtained 1560 and $1705 \mathrm{bp}$ fragments, respectively, both fragments contain a copy of the CR-B. The fragments were ligated into PstI/KpnI-digested pGreen vector to obtained pGMerMVB5. The clones were transformed into a disarmed strain of Agrobacterium tumefaciens, GV3101, by electroporation. Transformed, disarmed GV3101 cells were grown in LB liquid medium for $18 \mathrm{~h}$, pelleted by centrifugation, and resuspended in infiltration solution of
$10 \mathrm{mM} \mathrm{MgCl}_{2}$ and $100 \mu \mathrm{M}$ acetosyringone to achieve a final cell density of $1 \mathrm{OD}$ at $600 \mathrm{~nm}$. An equal volume of A. tumefaciens carrying pG-MerMVA11 and pGMerMVB5 cloned components were mixed, and used to infiltrate tomato and $N$. benthamiana seedlings, as previously described [37]. Inoculated and mock-inoculated test plants were assayed for MerMV presence in newly developing leaves by PCR amplification using the ACcore/ AVcore primers [44].

\section{Experimental host range}

Seeds of test plants (Table 2) were sown at three per 8-cmdiam pot. At least four seedlings at the three to four leaf stage, per each of three replicates, were biolistically inoculated with cloned, infectious MerMV DNA-A and -B components, as previously described [40]. Experimental controls consisted of tomato seedlings plants biolistically inoculated with the plasmid vector used for MerMV cloning, and non-inoculated tomato seedlings. Inoculated tests plants were maintained in insect-free greenhouse and observed for symptom development. At 3-4 week postinoculation, total DNA was isolated from test plants and assayed for presence of MerMV by PCR amplification using the degenerate primers, ACcore/AVcore [44]. The development of virus-like symptoms in test plants was recorded, and considered as further evidence of virus infection.

\section{Results}

\section{Viral DNA genomic component sequences}

The complete nt sequences for 20 MerMV DNA-A component clones were determined (Supplementary Table 4). PASC using SDT v. 1.0 [52] showed that the 20 cloned MerMV DNA-A components shared from 95.8 to $100 \% \mathrm{nt}$ identity with each other, indicating that the isolates represent a single MerMV species. As a group, they shared the highest nt identity with BDMV at 78.4-79\%, TGMV at $77.5-79.1 \%$, PYMV-TT at 77.8-78.8\%. However, these isolates also shared $91.8-92.1 \%$ with a begomoviral strain of MerMV from Venezuela (MerMV-VE) [AY508991]. The complete nt sequences for 26 clones for MerMV DNA-B component were determined. The 26 MerMV-B clones from PR shared 92.1-100\% nt identity with each other. Surprisingly MerMV DNA-B shared only 80.5-81.3\% nt identity with the DNA-B of the Venezuelan strain [AY508992] in spite of relatively high nt identity (91.8-92.1\%) shared between their DNA-A. The cloned DNA-B component sequences shared their highest nt identity with BGYMV-MX at $71.7-72.7 \%$, BDMV at 
Table 2 Experimental host range of Merremia mosaic virus determined by biolistic inoculation with infectious clones

\begin{tabular}{lll}
\hline Test species & Symptoms & PCR detection \\
\hline Capsicum annuum“Anaheim” & No symptoms & - \\
Cucurbita maxima "Big Max" & No symptoms & - \\
Datura stramonium & Mild leaf curling & + \\
Glycine max & No symptoms & - \\
Gossypium hirsutum & No symptoms & - \\
Hibiscus esculentus & No symptoms & - \\
Solanum lycopersicum "Humaya” & Mild leaf curl, yellow mosaic & - \\
Malva parviflora & No symptoms & + \\
Merremia aegyptia & Yellow mosaic, vein yellowing & + \\
M. quinquefolia & Yellow mosaic, vein yellowing & + \\
Nicotiana tabacum & Yellow mosaic, leaf curl & - \\
Phaseolus vulgaris & No symptoms & + \\
\hline
\end{tabular}

Test plants were assayed for virus infectivity by PCR using coat protein core primers, $(+)$ denotes virus infectivity $(-)$ denotes negative infectivity results
$71.2-71.6 \%$ and Macroptilium mosaic Puerto Rico virus at $70.8-71.3 \%$. The DNA-A and -B components of MerMV shared a $140 \mathrm{nt}$ common region (CR) at $97.9 \%$ nt identity indicating cognates of the same bipartite begomovirus species. Inspection of the CR revealed a cis-acting Repbinding site (GGGGG-AACT-GGGGG) [3] expected to confer replication specificity [22] that was identical to those of MerMV-VE, PYMV-PR, PYMV-GP, and PYMVVE.

\section{Phylogenetic relationship with other begomoviruses}

Phylogenetic trees reconstructions using the DNA-A and DNA-B component sequences of MerMV and selected begomoviruses for which sequences are available in the GenBank are presented in Fig. 1a, b. Analysis of both components placed MerMV with the bipartite begomoviruses from the New World. The MerMV DNA-A component was separated based on geography, isolates from PR grouped together separately from the VE isolate. The PR isolates were further separated into three subgroups based on the plant host in that one group each was isolated from tomato, Merremia spp., respectively, whereas the third group comprised isolates from both host plant species (Fig. 1a). Similarly, phylogenetic analysis of MerMV DNA-B components from PR formed two groups that each likewise grouped separately from the MerMV isolate reported from Venezuela. However, all of the PR isolates clustered as two separate groups, with one represented by the isolates that co-evolved with Merremia spp., and the second containing virus isolates originating from field-infected tomato or from Merremia spp. plants (Fig. 1b).

\section{Evidence for intermolecular and intramolecular recombination}

Using methods for recombination analysis available in Recombination Detection Program (RDP2) [47], and the highest acceptable probability of 0.01 to analyze the MerMV DNA-A components for evidence of possible recombination, a 592-nt fragment $\left(P\right.$ value $\left.4.590 \times 10^{-09}\right)$ located at the nt coordinates 1871-2462 (based on MerMVPR4H1), was detected as a predicted recombinant region. Thus, MerMV contained a predicted genomic fragment of a begomovirus closely related to Rhynchosia golden mosaic virus (RhGMV) [AF239671], as a putative minor parent). A second predicted recombination event that involved 1956-nt fragment located between nt coordinates 2463 and 1870 was identified as putative recombinant fragment most closely related to Bean golden mosaic virus (BGMV) [M88686] (major parent) (Fig. 2a). Extant species for the latter two putative parental viruses are known to occur in Puerto Rico. Based on RDP analysis [47] evidence of these two predicted inter-specific recombination event(s) was found for all 21 MerMV isolates, and also for the closest relative to MerMV from Puerto Rico identified independently from tomato plants in Venezuela, using BootScan [46], MaxChi [73], Chimaera [62], and SiScan [26] algorithms. The RDP analysis also detected a predicted intraspecific recombination event between the MerMV isolates PR64-H14 isolated from Merremia and PR23-H22, which was isolated from tomato. The latter recombination event was detected using 0.01 and 0.001 highest acceptable probability values for six isolates of the MerMV detected in Merremia spp., PR89-H40, PR89-H38, PR37H1, PR37-H2, PR37-H3 and PR4-H1, contained this 


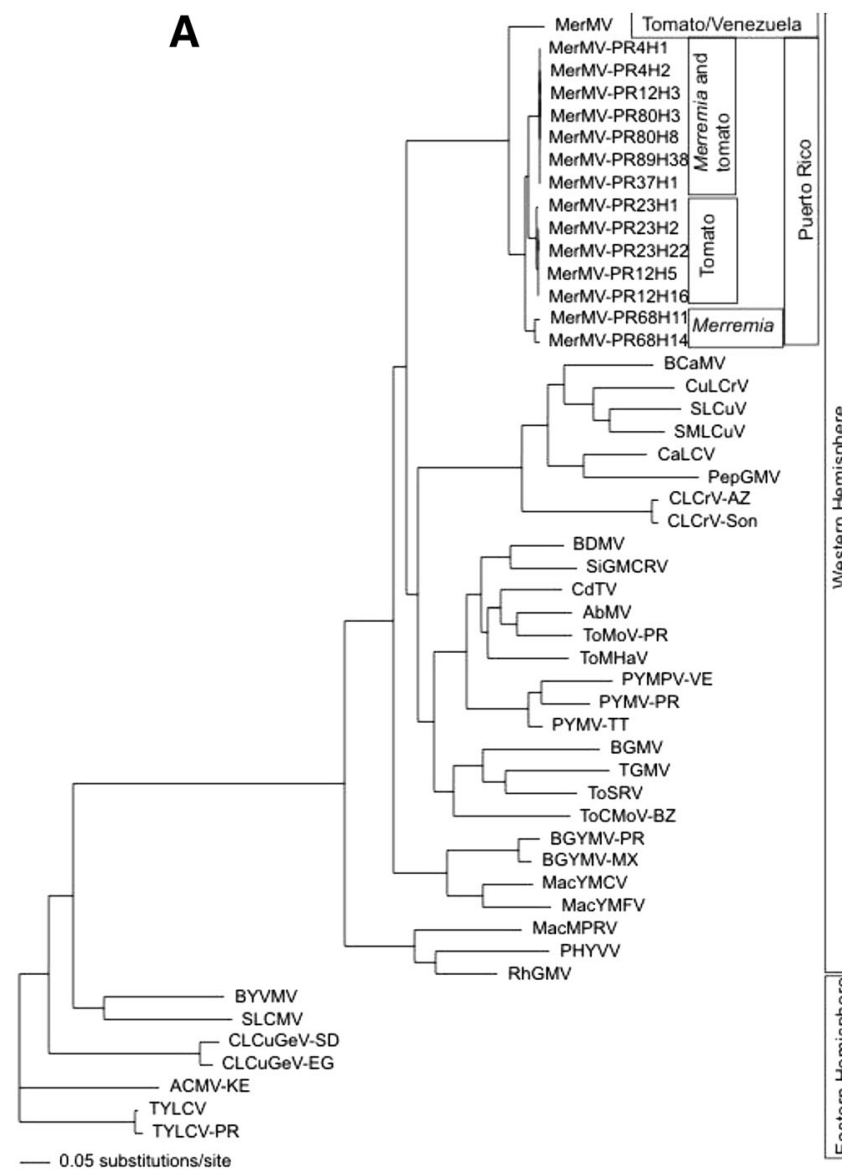

Fig. 1 Reconstructed phylogenetic trees showing the relationships between the Merremia mosaic virus (MerMV) isolates from symptomatic Merremia spp. and tomato plants collected in Puerto Rico a DNA-A or b DNA-B component trees. Trees were reconstructed using the Maximum likelihood (ML) method available in PAUP* software, using the Heuristic search option and the nucleotide substitution model $\operatorname{TrN}+\mathrm{I}+\mathrm{G}$ and $\mathrm{GTR}+\mathrm{I}+\mathrm{G}$ for

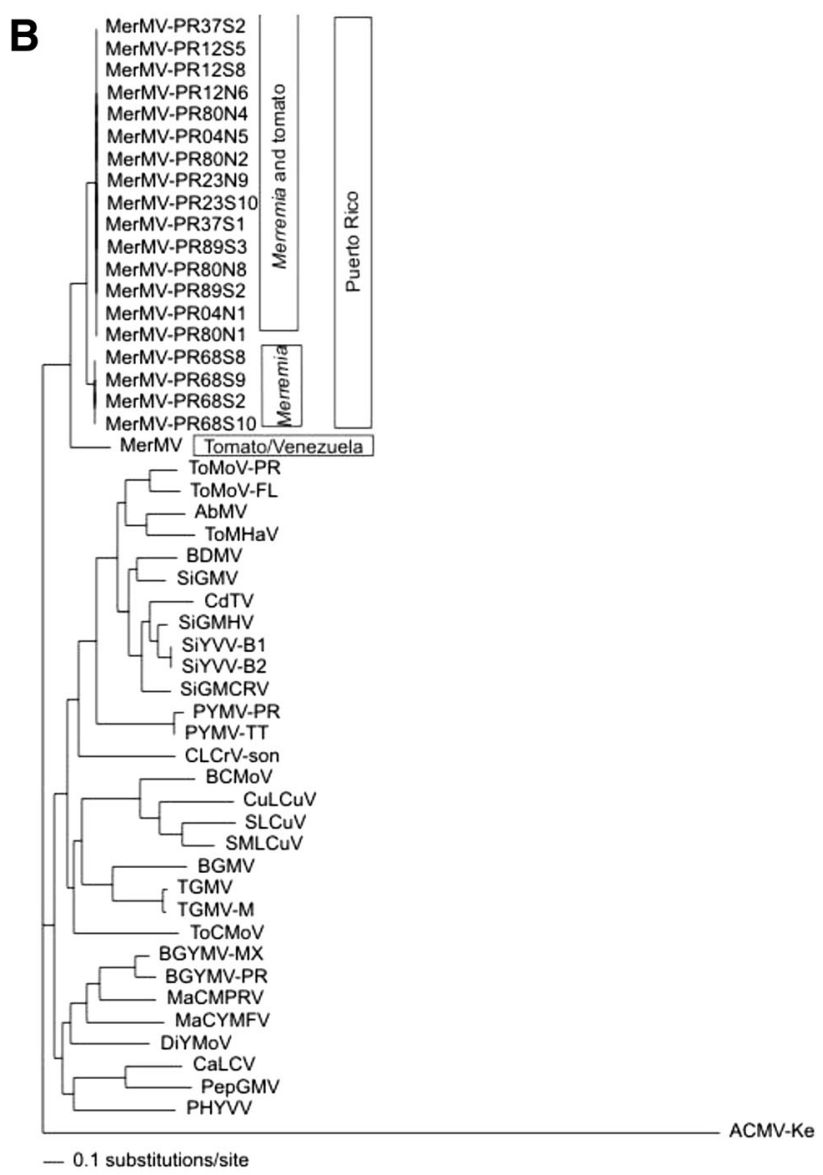

reconstructing the DNA-A and -B ML trees, respectively, as selected by hLRT in Modeltest3.7. The vertical lengths are arbitrary, and horizontal branch is proportional to the nucleotide substitution. The trees were rooted with DNA-A and DNA-B sequence the Old World ACMV-KE, respectively. The bar indicates 0.05 and 0.10 nucleotide substitutions, per site, for the DNA-A and -B components, respectively
Fig. 2 Results of the recombination events detected in MerMV DNA-A of MerMV based on the Chimaera method. The pink region indicates the left and right potential of the breakpoints. The green $=$ plot of BGMV nt sequences (parent); Blue = plot of RhGMV nt sequences (parent); Brown $=$ plot of MerMVPR4H1 nt sequences (recombinant) (color figure online)

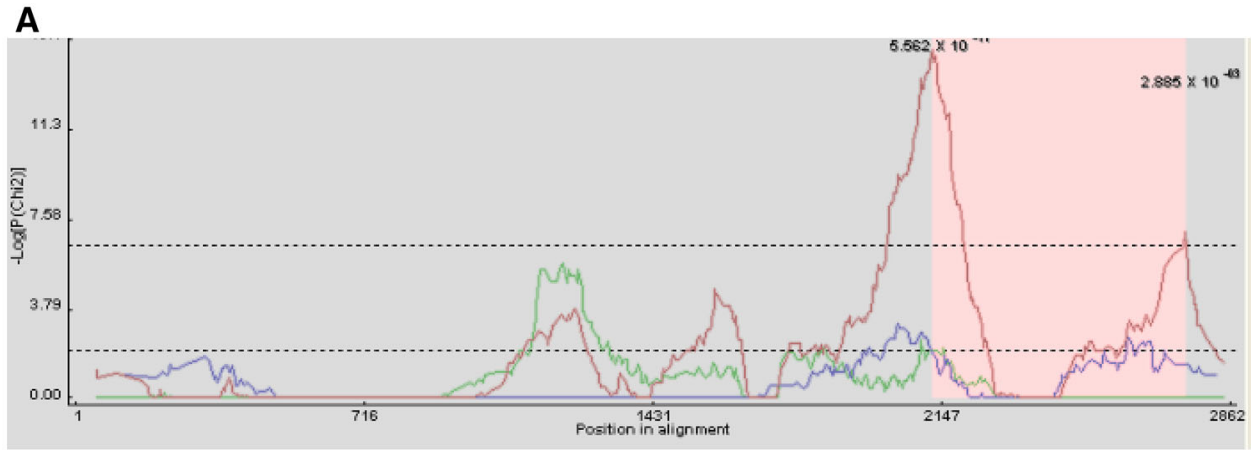

B intraspecific recombination event, at a $P$ value $3.406 \times 10^{-03}$. A 1604-nt fragment occurred between $n t$ coordinates 773 and 2376 (using PR89-H40 as the reference) shared between PR89-H40 (daughter) and PR64-H14 (major parent) (Fig. 2b). A smaller fragment of 953-nt, originating from isolate PR23-H22 (minor parent) is located between the nt coordinates 2367 and 772 (using PR89$\mathrm{H} 40$ as the reference). This potential recombinant fragment 
spans the $5^{\prime}$-end of $\mathrm{AC} 1, \mathrm{CR}$ and $5^{\prime}$-end of the coat protein gene (Fig. 2b). These intraspecific recombination event was identified by the algorithms, GENECONV [71], RDP, BootScan, MaxChi, Chimaera, and SiScan. The results were verified by reconstructing a phylogenetic tree with and without the predicted recombinant fragments (data not shown). The shift of the recombinant sequence from the original position, as a recombinant, to a different clade minus the recombinant sequence provided robust support for the recombination hypothesis.

\section{Infectivity of clones by biolistic inoculation}

The MerMV-inoculated M. quinquefolia and M. aegyptia developed mild yellow mosaic and vein yellowing symptoms, whereas, tomato plants exhibited mild leaf curl and distortion, and Datura stramonium showed mild leaf curling symptoms (Table 2). Symptoms that developed in $M$. quinquefolia and tomato plants inoculated with MerMV were like those observed under field conditions (Fig. 3). Total DNA purified from the newly developing leaves of inoculated test plants was analyzed for virus presence e.g. systemic infection, using degenerate PCR primers to amplify the 'core' region of the CP gene [44], followed by cloning, and confirmatory DNA sequencing.

\section{Host range of MerMV}

Results indicated that the experimental host range of MerMV was narrow in that it infected only species in the Solanaceae and Convolvulaceae, two of the five families tested here. MerMV was detectable in D. stramonium, M. aegyptia, M. quinquefolia, N. benthamiana, and S. lycopersicum, all of which were symptomatic. Virus was not detectable in the other inoculated test plant species, representing the three additional plant families, the Cucurbitaceae, Fabaceae, or Malvaceae (Table 1).

Seedlings of the S. lycopersicum, M. quinquefolia and $N$. benthamiana plants that were agro-infiltrated with the cloned begomoviral components, pG-MerMVA11 and pGMerMVB5, developed systemic symptoms like those observed when biolistic particle bombardment and/or whitefly-mediated transmission was used for inoculation. And, symptoms in tomato and $M$. quinquefolia were indistinguishable from those observed in field-collected, symptomatic plants.

\section{Discussion}

Commercial tomato crops in the tropics and subtropics have suffered from an increasing number of whiteflytransmitted begomovirus pathogens during the last 20 years, particularly where the B type of B. tabaci has become established [13, 16, 59]. Here, robust evidence has been provided for the presence of a bipartite begomovirus infecting cultivated tomato, and associated with two native, uncultivated eudicot species, $M$. quinquefolia and $M$. aegyptia. Representative isolates of MerMV [8] were cloned from symptomatic field samples collected from different geographic locations of Puerto Rico (Table 1). Phylogenetic analysis of the DNA-A and -B component sequences indicate that MerMV is a unique, previously unidentified bipartite begomovirus from Puerto Rico. The $140 \mathrm{nt}$ CR of the DNA-A and -B components of this virus shared $97.9 \%$ indicating they are likely cognate genomic components of MerMV and that they are apparently share sufficient identity to promote REP binding to initiate viral replication and carry out other functions critical to the viral life cycle. At the same time, the A and B components nonetheless exhibited somewhat greater divergence compared to many begomoviruses from crops for which cloned $\mathrm{A}$ and $\mathrm{B}$ genomic components are now available, yet virus from cultivated and wild hosts did not vary noticeably with respect to host-related divergence [41]. This observation may be explained by the possibility that this virus has only recently emerged into tomato from its indigenous, longtime weed hosts, and lacks sufficient opportunities to vary, or that infection of tomato by MerMV relies on the repeated introduction of the virus population to tomato from the wild host, instead of the serial passage through a genetically uniform cultivated host, as might be expected by a
Fig. 3 Symptoms of a Merremia mosaic virus (MerMV) in Merremia aegyptia, b mock-inoculated control
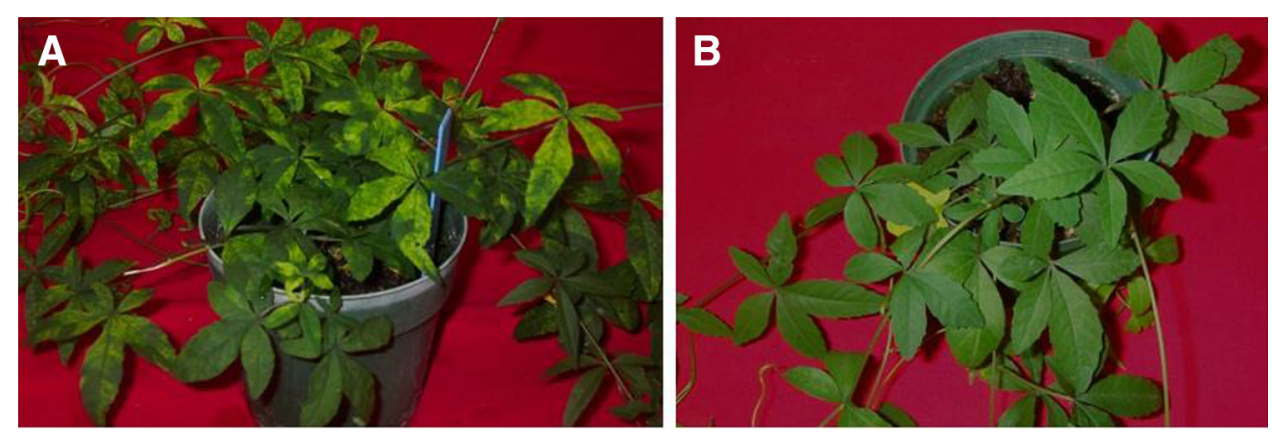
fully-adapted virus, thereby retaining detectable intrapopualation variation, accounted for by the observed divergence in CR sequences (data not shown). Nonetheless, although many cognate components share high sequence identity, several others recently emerging begomoviruses have been reported to diverge to a greater extent, including the CR-A and DNA-B for CaLCV [34] and CLCrV [44], which have been found to be recent recombinants.

Phylogenetic analysis of the MerMV DNA-A component indicates that it is a New World begomovirus in that it groups with other begomoviruses in a well-supported clade (bootstrap value 73) that contains MerMV-VE, a strain of MerMV reported from commercial tomato plants in Venezuela (Table 3), with the most closely related virus to MerMV, Bean dwarf mosaic virus (BDMV), described from Colombia, at $71 \%$. Although it is not uncommon among tomato-infecting viruses to also infect bean, either naturally or experimentally [53, 54, 60], until now, indigenous convolvulaceous species have not been implicated as wild host reservoirs for begomoviruses recently emerging in a crop species.

The DNA-A component sequence of the Venezuelan isolate shared $91 \%$ nt identity with its' Puerto Rican counterparts, and based on ICTV guidelines is considered a strain of MerMV. However, the MerMV-PR DNA-B genomic component shared low nt identity with MerMVVE, at $72.3 \%$ (Supplementary Table 4). Generally, the DNA-B component of different begomoviral species share a lower overall nt identity than do their corresponding DNA-A component, respectively [44] but not isolates and/ or strains of the same viral species. In spite of the relatively low, shared nt identity, at $72.3 \%$, between the DNA-B component of MerMV-PR and MerMV-VE, the common region for each isolate shared $97.7 \%$ nt identity, indicating different evolutionary pathways for the two B components of these closely related begomovirus isolates. Evidence

Table 3 Percentage identity of DNA-A (MerMV-PR80H3) and DNA-B (MerMV-PR80N4) component sequence of Merremia mosaic virus (MerMV) from Puerto Rico, compared to its closest relatives among other New World begomoviruses

\begin{tabular}{lll}
\hline MerMV isolate & DNA-A & DNA-B \\
\hline MerMV-PR68 & 95.4 & 89.3 \\
MerMV-PR12 & 96.9 & 99.8 \\
MerMV-VE & 91.0 & 72.6 \\
BDMV & 70.9 & 54.6 \\
PYMTV-TT & 72.7 & 53.7 \\
PYMV-PR & 69.6 & 53.7 \\
SiGMCRV & 70.3 & 54.7 \\
ToMoV-PR & 68.7 & 53.5 \\
\hline
\end{tabular}

supporting this possibility is illustrated by the results of a study in which the BDMV DNA-B component was able to acquire most of the CR from unrelated ToMoV DNA-A in intermolecular recombination [36]. Supporting evidence is also provided by evidence of intermolecular recombination between two distinct viruses, Sri Lankan cassava mosaic virus (SLCMV) DNA-A and Indian cassava mosaic virus (ICMV) DNA-B that yielded SLCMV DNA-B [69].

The ability to transmit MerMV between Merremiatomato and two Merremia species, resulting in symptom phenotypes reminiscent of the respective wild type and the symptom phenotype that was observed in cultivated tomato, corroborated the hypothesis based on their provisional molecular identification evidence that the same virus is capable of infecting at least two Merremia species and tomato, and that MerMV is a distinct whitefly-transmitted begomoviral species. In addition to infecting tomato and Merremia weeds, MerMV also experimentally infect the Datura and tobacco (Table 2) and also reported to infect hot pepper (Capsicum chinense), sweet pepper ( $C$. annuum) and the weed Euphorbia heterophylla in Belize [49]. These results collectively suggesting that MerMV have broader host ranges than previously thought. Thus, both crops and native weeds are considered a natural reservoir of begomoviruses like MerMV and it is reasonable to speculate that these hosts might play a role on their epidemics and diversity [24].

Since its introduction in Puerto Rico in $\sim 1990$, the exotic B biotype whitefly vector [16] has been responsible for dispersing three tomato-infecting begomoviruses, MerMV, PYMV, ToMoV, and Tomato yellow leaf curl virus $[8,25]$ to tomato crops in Puerto Rico. A survey of $B$. tabaci [14] indicated that the B mitotype predominated as the vector of begomoviruses on the island [6]. The importance of the B type as a vector of these four begomoviruses in Puerto Rico may be due in part to the wellknown capacity of the B biotype to colonize at least 500 different plant hosts [29], compared to the more moderate host range of the native Sida race [6] and the nearly monophagous Jatropha race [5]. None of these viruses were found previously in tomato in Puerto Rico until after the introduction of the B biotype vector. Nonetheless, it is difficult to envision how a purported co-evolution between capsid-vector specificity [32, 48, 68] can be overcome so dramatically, unless sheer numbers of this highly fecund $[18,66]$ vector compensate for the putative inefficient transmissibility of New World viruses by an Old-World vector, however, the basis for differences in begomovirus transmission efficiency (or competency) by the whitefly vector are poorly understood.

Although both the Sida mitotype (previously, race) has been known to colonize M. quinquefolia and M. aegyptia in Puerto Rico [6, 7] MerMV had not been reported 
previously in tomato in Puerto Rico [4, 42]. This scenario suggests that the emergence of MerMV in tomato is due to several factors. First, the B biotype, which has been shown to have its center of endemism in the North AfricaMediterranean-Middle East region, was introduced into Puerto Rico during the late 1980s, where it became established as an invasive species, exhibiting high fecundity, and producing up to 300 offspring in a lifetime. Second, the exotic B type has a broad host range and was found to colonize tomato and M. quinquefolia, whereas, the endemic Sida and Jatropha races of $B$. tabaci were not known to colonize tomato and primarily colonized rutaceous species, respectively, and the Sida race colonized cultivated legumes such as bean and pigeon pea [7]. Third, the B type exhibits long-distance dispersal behavior, compared to short distance flight by B. tabaci that are indigenous to the Americas and Caribbean region, making spread from wild hosts to cultivated tomato more likely. These observations suggest that although MerMV is a New World virus, and the B type is an Old World vector, it is nonetheless a competent vector of MerMV between $M$. quinquefolia to tomato, even though they are not always found in close proximity.

Acknowledgement This publication is dedicated to the memory of our esteemed colleague, collaborator, and friend Dr. Julio BirdPinero, University of Puerto Rico, Rio Piedras, who passed away June 29,2012 . His contributions span the discovery and characterization of the first begomoviruses studied from the Caribbean region, long before the establishment of the Begomovirus genus, development of the concept of 'host races' of Bemisia tabaci based on distinct phenotypic characteristics, including host range and begomovirus transmission, and his pioneering work into the etiology of sugarcane diseases in the Caribbean region, among many others. This project was funded by HATCH funds awarded to the University of Puerto Rico and/or the University of Arizona during 1998-present. This project was funded by the National Plan for Science, Technology and Innovation (MAARIFAH), King Abdulaziz City for Science and Technology, Kingdom of Saudi Arabia, Award No. BIO2833.

\section{References}

1. Altschul SF, Gish W, Miller W, Myers EW, Lipman DJ. Basic local alignment search tool. J Mol Biol. 1990;215:403-10.

2. Ambrozevicius LP, Calegario RF, Fontes EP, Carvalho MG, Zerbini FM. Genetic diversity of begomovirus infecting tomato and associated weeds in Southeastern Brazil. Fitopatol Bras. 2002;27:372-7.

3. Argüello-Astorga GR, Guevara-González RG, Herrera-Estrella LR, Rivera-Bustamante RF. Geminivirus replication origins have a group-specific organization of iterative elements: a model for replication. Virology. 1994;1994(203):90-100.

4. Baumann K, Idris AM, Bird J, Brown JK. Merremia mosaic virus is a begomovirus species originating from indigenous weeds in PR that is recently adapted to tomato. Phytopathology. 2005;2005(95):S7.

5. Bird J. A whitefly transmitted mosaic of Jatropha gossypifolia. Tech Pap Agric Exp Stn PR. 1957;22:35.
6. Bird J, Maramorosch K. Viruses and virus diseases associated with whiteflies. Adv. Vir. Res. 1987;22:55-110.

7. Bird J, Sanchez RL, Julia FJ. Rugaceous whitefly-transmitted viruses in Puerto Rico. In: Bird J, Maramorosch K, editors. Tropical diseases of legumes. New York: Academic Press; 1975. p. 3-26.

8. Bird J, Idris AM, Rogan D, Brown JK. Introduction of exotic Tomato yellow leaf curl virus-Israel in tomato Puerto Rico. Plant Dis. 2001;85:1028.

9. Bisaro DM. Geminivirus DNA replication. In: De Pamphilis ML, editor. DNA replication in eukaryotic cells. Cold Spring Harbor: Cold Spring Harbor NY Laboratory Press; 1996. p. 833-54.

10. Briddon RW, Stanley J. Subviral agents associated with plant single-stranded DNA viruses. Virology. 2006;344:198-210.

11. Briddon RW, Bull SE, Amin I, Idris AM, Mansoor S, Bedford ID, Dhawan P, Rishi N, Siwatch SS, Abdel-Salam AM, Brown JK, Zafar Y, Markham PG. Diversity of DNA beta, a satellite molecule associated with some monopartite begomoviruses. Virology. 2003;312:106-21.

12. Brown JK. Bemisia: phylogenetic biology of the Bemisia tabaci sibling species group. In: Stansly PA, Naranjo SE, editors. Bemisia: bionomics and management of a global pest. Dordrecht: Springer; 2010. p. 31-67.

13. Brown JK, Bird J. Whitefly-transmitted geminiviruses in the Americas and the Caribbean Basin: past and present. Plant Dis. 1992;76:220-5.

14. Brown JK, Bird J. Introduction of an exotic whitefly (Bemisia) vector facilitates secondary spread of Jatropha mosaic virus, a geminivirus previously vectored exclusively by the Jatropha biotype. In: Gerling D, Mayer RT, editors. Bemisia'95: taxonomy, biology, damage, control and management. Wimborne: Intercept; 1996. p. 351-3.

15. Brown JK. The Bemisia tabaci complex: genetic and phenotypic variability drives begomovirus spread and virus diversification. Plant Dis. 2007. http://www.apsnet.org/online/feature/btabaci/.

16. Brown JK, Frohlich D, Rosell R. The sweetpotato/silverleaf whiteflies: biotypes of Bemisia tabaci (Genn.), or a species complex? Ann Rev Entomol. 1995;40:511-34.

17. Brown JK, Zerbini FM, Navas-Castillo J, Moriones E, RamosSobrinho R, Silva JCF, Briddon RW, Hernandez-Zepeda C, Idris AM, Malathi VG, Martin DP, Rivera-Bustamante R, Ueda S, Varsani A. Revision of Begomovirus taxonomy based on pairwise sequence comparisons. Arch Virol. 2015;160:1593-619.

18. Costa HS, Brown JK. Variation in biological characteristics and in esterase patterns among populations of Bemisia tabaci (Genn.) and the association of one population with silverleaf symptom development. Entomol Exp Appl. 1991;61:211-9.

19. da Silva SJ, Castillo-Urquiza GP, Hora Junior BT, Assuncao IP, Lima GS, Pio-Ribeiro G, Mizubuti ES, Zerbini FM. High genetic variability and recombination in a begomovirus population infecting the ubiquitous weed Cleome affinis in northeastern. $\mathrm{Br}$ Arch Virol. 2011;156:2205-13.

20. Doyle JJ, Doyle JL. Isolation of plant DNA from fresh tissue focus (Madison). 1990;12:13-5.

21. Fauquet CM, Sawyer S, Idris AM, Brown JK. Phylogeny and evidence for high degree of recombination in tomato-infecting begomoviruses from the Old World. Phytopathology. 2005;95:549-55.

22. Fontes EPB, Eagle PA, Sipe PS, Luckow VA, Hanley-Bowdoin L. Interaction between a geminivirus replication protein and origin DNA is essential for viral replication. J Biol Chem. 1994;269:8459-65.

23. Frischmuth T, Engel M, Lauster S, Jeske H. Nucleotide sequence evidence for the occurrence of three distinct whitefly-transmitted Sida-infecting bipartite geminiviruses in Central America. J Gen Virol. 1997;78:2675-82. 
24. Garcia-Andres S, Monci F, Navas-Castillo J, Moriones E. Begomovirus genetic diversity in the native plant reservoir Solanum nigrum: evidence for the presence of a new virus species of recombinant nature. Virology. 2006;350:433-42.

25. Garcia-Andres S, Tomas DM, Sanchez-Campos S, Navas-Castillo J, Moriones E. Frequent occurrence of recombinants in mixed infections of tomato yellow leaf curl disease-associated begomoviruses. Virology. 2007;365:210-9.

26. Gibbs MJ, Armstrong JS, Gibbs AJ. Sister-scanning: a Monte Carlo procedure for assessing signals in recombinant sequences. Bioinformatics. 2000;16:573-82.

27. Gill R, Brown JK. Systematics of Bemisia and Bemisia relatives: can molecular techniques solve the Bemisia tabaci complex conundrum - a Taxonomist's viewpoint Chapter 1. In: Stansly PA, Naranjo SE, editors. Bemisia: bionomics and management of a global pest. Dordrecht: Springer; 2010. p. 5-29.

28. Graham AP, Martin DP, Roye ME. Molecular characterization and phylogeny of two begomoviruses infecting Malvastrum americanum in Jamaica: evidence of the contribution of interspecies recombination to the evolution of malvaceous weed-associated begomoviruses from the Northern Caribbean. Vir Genes. 2010;40:256-66.

29. Greathead AH. Host plants. In: Cock MJW, editor. Bemisia tabaci-a literature survey. Silwood Park: $\mathrm{CAB}$ International Institute of Biological Control; 1986. p. 17-26.

30. Hanley-Bowdoin L, Settlage SB, Orozco BM, Nagar S, Robertson D. Geminiviruses-models for plant DNA replication transcription and cell cycle regulation. Curr Biol. 1999;18:71-106.

31. Harrison BD. Advances in geminivirus research. Annu Res Phytopathol. 1985;23:55-82.

32. Harrison BD, Robinson DJ. Natural genomic and antigenic variation in whitefly-transmitted geminiviruses (begomoviruses). Annu Rev Phytopathol. 1999;37:369-98.

33. Hernández-Zepeda C, Idris AM, Carnevali G, Brown JK, Moreno-Valenzuela OA. Molecular characterization and phylogenetic relationships of two new bipartite begomovirus infecting malvaceous plants in Yucatan Mexico. Vir Genes. 2007;35:369-77.

34. Hill JE, Strandberg JO, Hiebert E, Lazarowitz SG. Asymmetric infectivity of pseudorecombinants of cabbage leaf curl virus and squash leaf curl virus: implications for bipartite geminivirus evolution and movement. Virology. 1998;250:283-92.

35. Hosseinzadeh MR, Shamsbakhsh M, Kazempour Osalou S, Brown JK. Phylogenetic relationships recombination analysis and genetic variability among diverse variants of Tomato yellow leaf curl virus in Iran and the Arabian Peninsula: further support for a TYLCV-center of diversity. Arch Virol. 2014;158:485-97.

36. Hou YM, Gilbertson RL. Increased pathogenicity in a pseudorecombinant bipartite geminivirus correlates with intermolecular recombination. J Virol. 1996;70:5430-6.

37. Hussain M, Mansoor S, Iram S, Zafar Y, Briddon RW. The hypersensitive response to tomato leaf curl New Delhi virus nuclear shuttle protein is inhibited by transcriptional activator protein. Mol Plant Microbe Interact. 2007;20:1581-8.

38. Idris AM, Brown JK. Sinaloa tomato leaf curl geminivirus: biological and molecular evidence for a new subgroup III virus. Phytopathology. 1998;88:648-57.

39. Idris AM, Lee SH, Lewis EA, Bird J, Brown JK. Three tomatoinfecting begomoviruses from Puerto Rico. Phytopathology. 1998;88:S42.

40. Idris AM, Smith SE, Brown JK. Ingestion, transmission, and persistence of Chino del tomate virus (CdTV), a New World begomovirus, by Old and New World biotypes of the whitefly vector Bemisia tabaci. Ann Appl Biol. 2001;139:145-54.

41. Idris AM, Hiebert E, Bird J, Brown JK. Two newly described begomoviruses of Macroptilium lathyroides and common bean. Phytopathology. 2003;93:774-83.
42. Idris AM, Bird J, Brown JK. Infectivity of Merremia mosaic virus clones: a bipartite begomovirus from Puerto Rico American Phytopathological Society-Caribbean Division Cartagena Colombia September. Phytopathology. 2007;97:S174.

43. Idris AM, Mills-Lujan K, Baumann K, Brown JK. Melon chlorotic leaf curl virus: characterization and differential reassortment with closest relatives reveals adaptive virulence in the SLCV clade and host shifting by the host-restricted BCaMV. J Virol. 2008;82:1959-67.

44. Idris A, Al-Saleh M, Amer M, Abdalla O, Brown J. Introduction of Cotton leaf curl Gezira virus into the United Arab Emirates. Plant Dis. 2014;98:1593.

45. Lazarowitz SG. Geminiviruses: genomes structure and gene function. Crit Rev Plant Sci. 1992;11:327-49.

46. Martin DP, Posada D, Crandall KA, Williamson C. A modified bootscan algorithm for automated identification of recombinant sequences and recombination breakpoints. AIDS Res Hum Retrovir. 2005;21:98-102.

47. Martin DP, Lemey P, Lott M, Moulton V, Posada D, Lefeuvre P. RDP3: a flexible and fast computer program for analyzing recombination. Bioinformatics. 2010;26:2462-3.

48. McGRATH PF, Harrison BD. Transmission of tomato leaf curl geminiviruses by Bemisia tabaci: effects of virus isolate and vector biotype. Ann Appl Biol. 1995;126:307-16.

49. McLaughlin PD, McLaughlin WA, Maxwell DP, Roye ME. Identification of begomoviruses infecting crops and weeds in Belize. Plant Virus. 2008;2:58-63.

50. Melgarejo TA, Kon T, Rojas MR, Paz-Carrasco L, Zerbini FM, Gilbertson RL. Characterization of a new world monopartite begomovirus causing leaf curl disease of tomato in Ecuador and Peru reveals a new direction in geminivirus evolution. J Virol. 2013;87:5397-413.

51. Monci F, Sanchez-Campos S, Navas-Castillo J, Moriones E. A natural recombinant between the geminiviruses Tomato yellow leaf curl Sardinia virus and Tomato yellow leaf curl virus exhibits a novel pathogenic phenotype and is becoming prevalent in Spanish populations. Virology. 2002;303:317-26.

52. Muhire BM, Varsani A, Martin DP. SDT: a virus classification tool based on pairwise sequence alignment and identity calculation. PLoS ONE. 2014;9:e108277.

53. Navas-Casillo J, Sanchez-Campos Diaz JA. Tomato yellow leaf curl virus-is causes a novel disease of common bean and severe epidemics in tomato in Spain. Plant Dis. 1999;83:29-32.

54. Navot N, Zeidan M, Pichersky E, Zamir D, Czosnek H. Use of the polymerase chain reaction to amplify tomato yellow leaf curl virus DNA from infected plants and viruliferous whiteflies. Phytopathology. 1992;82:1199-202.

55. Nawaz-ul-Rehman MS, Nahid N, Mansoor S, Briddon RW, Fauquet CM. Post-transcriptional gene silencing suppressor activity of two non-pathogenic alphasatellites associated with a begomovirus. Virology. 2010;405:300-8.

56. Ooi K, Ohshita S, Ishii I, Yahara T. Molecular phylogeny of geminivirus infecting wild plants in Japan. J Plant Res. 1997;110:247-57.

57. Padidam M, Sawyer S, Fauquet CM. Possible emergence of new geminiviruses by frequent recombination. Virology. 1999;265:218-25.

58. Pita J, Fondong V, Sangare A, Otim-Nape G, Ogwal S, Fauquet C. Recombination pseudorecombination and synergism of geminiviruses are determinant keys to the epidemic of severe cassava mosaic disease in Uganda. $J$ Gen Virol. 2001;82:655-65.

59. Polston JE, Anderson PK. The emergence of whitefly-transmitted geminiviruses in tomato in the western hemisphere. Plant Dis. 1997;81:1358-69. 
60. Polston JE, Hiebert E, McGovern RJ, Stansly PA, Schuster DJ. Host range of tomato mottle virus, a new geminivirus infecting tomato in Florida. Plant Dis. 1993;77:1181-4.

61. Posada D, Crandall KA. Modeltest: testing the model of DNA substitution. Bioinformatics. 1998;14:817-8.

62. Posada D, Crandall KA. Evaluation of methods for detecting recombination from DNA sequences: computer simulations. Proc Nat Acad Sci. 2001;98:13757-62.

63. Riley L, Dunal L. Identification of a natural weed host of tomato mottle geminivirus in Florida. Plant Dis. 1994;78:1102-6.

64. Rojas MR, Hagen C, Lucas WJ, Gilbertson RL. Exploiting chinks in the plant's armor: evolution and emergence of geminiviruses. Annu Rev Phytopathol. 2005;243:361-94.

65. Romay G, Geraud-Pouey F, Chirinos DT, Galindo-Castro I, Franco MA. Molecular variability of Merremia mosaic virus infecting tomatoes in Venezuela. Aust Plant Dis Notes. 2016;11:11. https://doi.org/10.1007/s13314-016-0198-1.

66. Rubinstein G, Czosnek H. Long-term association of tomato yellow leaf curl virus with its whitefly vector Bemisia tabaci: effect on the insect transmission capacity, longevity and fecundity. J Gen Virol. 1997;78:2683-9.

67. Sanchez-Campos S, Martinez-Ayala A, Marquez-Martin B, Aragon-Caballero L, Navas-Castillo J, Moriones E. Ful- filling Koch's postulates confirms the monopartite nature of tomato leaf deformation virus: a begomovirus native to the New World. Virus Res. 2013;173:286-93.

68. Sanz Al, Fraile A, Gallego JM, Malpica JM, Garcia-Arenal F. Genetic variability of natural populations of the cotton leaf curl geminivirus a single-stranded DNA virus. J Mol Evol. 1999;49:672-81.

69. Saunders K, Salim N, Mali VR, Malathi VG, Briddon R, Markham PG, Stanley J. Characterisation of Sri Lankan cassava mosaic virus and Indian cassava mosaic virus: evidence for acquisition of a DNA B component by a monopartite begomovirus. Virology. 2002;293:63-74.

70. Saunders K, Norman A, Gucciardo S, Stanley J. The DNA beta satellite component associated with Ageratum yellow vein disease encodes an essential pathogenicity protein (beta $\mathrm{C} 1$ ). Virology. 2004;324:37-47.

71. Sawyer S. Statistical tests for detecting gene conversion. Mol Biol Evol. 1989;6:526-38.

72. Silva S, Castillo-Urquiza G, Hora-Júnior B, Assunção I, Lima G, Pio-Ribeiro G, Mizubuti E, Zerbini F. Species diversity phylogeny and genetic variability of begomovirus populations infecting leguminous weeds in Northeastern. Brazil Plant Pathol. 2012;61:457-67.

73. Smith JM. Analyzing the mosaic structure of genes. J Mol Evol. 1992;34:126-9.

74. Swofford DL. "PAUP*. Phylogenetic analysis using parsimony (* and other methods). Version 4." 2003.

75. Tamura K, Peterson D, Peterson N, Stecher G, Nei M, Kumar S. MEGA5: molecular evolutionary genetic analysis using Maximum Likelihood, evolutionary distance, and maximum parsimony methods. Mol Biol Evol. 2011;28:2731-9.

76. Unseld S, Ringel M, Konrad A, Lauster S, Frischmuth T. Virusspecific adaptations for the production of a pseudorecombinant virus formed by two distinct bipartite geminiviruses from Central America. Virology. 2000;274:179-88.

77. Varsani A, Martin DP, Navas-Castillo J, Moriones E, HernándezZepeda C, Idris A, Zerbini FM, Brown JK. Revisiting the classification of curtoviruses based on genome-wide pairwise identity. Adv Virol. 2014;159:1873-82.

78. Wyatt SD, Brown JK. Detection of subgroup III geminivirus isolates in leaf extracts by degenerate primers and polymerase chain reaction. Phytopathology. 1996;86:1288-93.

79. Zerbini FM, Briddon RW, Idris A, Martin DP, Moriones E, Navas-Castillo J, Rivera-Bustamante R, Roumagnac P, Varsani A, ICTV Report Consortium. ICTV virus taxonomy profile: geminiviridae. J Gen Virol. 2017;98:131-3.

80. Zhou X. Advances in understanding begomovirus satellites. Ann Rev Phytopathol. 2013;51:357-81. 